\title{
SOBRE SONETOS, DISCURSOS E JORNAIS: SÁTIRA E GALHOFA NO CONTO “AURORA SEM DIA", DE MACHADO DE ASSIS
}

\section{About sonnets, speech and newspapers: satar and galhofa in the tale "Aurora sem dia", by Machado de Assis}

Resumo: Publicado em 1870 no Jornal das Famílias e em 1873 na coletânea Histórias da meia-noite (1873), o conto "Aurora sem dia", de Machado de Assis, apresenta uma sátira sobre poetas e políticos de pouco talento. Luís Tinoco, o protagonista, tornase escritor da noite para o dia e publica os seus sonetos no jornal Correio Mercantil, um espaço privilegiado de difusão de suas fantasias. Quando se torna deputado, ele espera que seus discursos sejam debatidos na imprensa. Este artigo analisa a relação entre a sátira do conto e a linguagem satírica do Correio Mercantil, que atacava os adversários por meio do humor. Concluise que o conto de Machado de Assis não é apenas de uma representação do universo da imprensa, mas também reflete a linguagem jornalística da época.

Palavras-chave: Imprensa. Machado de Assis. Correio Mercantil.
Abstract: Published in 1870 in the Jornal das Familias, and in 1873, in the collection Histórias da meia-noite (1873), Machado de Assis' tale "Aurora sem dia" features a satire about poets and politicians of little talent. Luís Tinoco, the protagonist, becomes an overnight writer and publishes his sonnets in the newspaper Correio Mercantil, a privileged field for the diffusion of his fantasies. When he becomes a deputy, he expects his speeches to be debated in the press. This article analyzes the relationship between the satire of the tale and the satirical language of Correio Mercantil, which attacked opponents through humor. We conclude that Machado de Assis' tale is not only a representation of the press universe, but also reflects the journalistic language of that time.

Keywords: Press. Machado de Assis. Correio Mercantil. 
- Sobre sonetos, discursos e jornais: sátira e galhofa no conto "Aurora sem dia", de Machado de Assis

As últimas décadas têm revelado um redirecionamento dos estudos literários quando o assunto trata da pesquisa em jornais. Vista com desconfiança pelos pesquisadores por conta dos interesses pessoais e da subjetividade da linguagem que se escondem por trás dos gêneros - sejam eles jornalísticos ou literários -, a imprensa escrita sofreu um preconceito que parece superado. No Brasil, um dos pioneiros na exploração de matériaprima oferecida pelos jornais foi Gilberto Freyre (1979), que estudou a partir dos registros da imprensa o comportamento dos escravos africanos e suas relações com a sociedade patriarcal no período imperial, bem como a influência da presença dos ingleses no Brasil. Em seguida, outros pesquisadores também passaram a recorrer aos jornais para pesquisar aspectos sociais e culturais do Brasil, a exemplo de Emília Viotti da Costa $(2012,1998)$, Edgard Carone (1974) e Fernando Henrique Cardoso (1962). No final da década de 1960, muitos estudos acadêmicos passaram a ser realizados com consultas a periódicos para análises de aspectos sociais e políticos ou obtenção de dados de natureza econômica ou demográfica.

Desde então, os jornais e as revistas deixaram de ser encarados com desconfiança enquanto fonte documental, pois muitos aspectos antes negligenciados pelos pesquisadores, como a tiragem, a área de circulação, as relações com partidos políticos e grupos econômicos e o comportamento dos leitores, agora fazem parte do escopo de pesquisas que procuram evidenciar os meios de produção e recepção do discurso histórico-jornalístico, "sempre com resultados originais e postura muito distante da tão temida ingenuidade" (LUCA, 2008, p. 117).

No campo dos estudos literários, não se pode pensar a história da literatura sem a participação direta ou indireta dos jornais e das revistas. Afinal, durante muito tempo esse foi o único meio de publicação da produção literária nacional. Os escritores trabalhavam nas redações como revisores, tradutores ou redatores e dependiam da circulação dos periódicos para chegar ao público leitor. Nos espaços destinados à literatura, como os folhetins, eram publicados romances, contos, poemas e crônicas que mais tarde, por vezes, também apareciam no formato de livro. Por causa disso, tornouse comum investigar exemplares antigos em busca de textos desconhecidos de autores reconhecidos; de textos de autores desconhecidos (a produção de autoria feminina é o maior exemplo) ${ }^{2}$; das primeiras versões de narrativas publicadas posteriormente em livro com fins de comparação (como os estudos acerca das obras de Machado de Assis); e de eventos históricos registrados na imprensa e que receberam um tratamento ficcional (o caso de Erico Verissimo é um exemplo) ${ }^{3}$.

2 Ver Zinani (2019).

3 Ver Alves (2018). 
Mais recentemente, pesquisas procuram mostrar que o papel da imprensa vai muito além de ser uma fonte primária para constatar a existência do registro literário. Olhando para a forma do jornal e da revista, que são meios de comunicação interessados em entregar um produto que prenda o leitor, os pesquisadores revelam que a linguagem jornalística tem uma relação estreita com a linguagem literária e isso ajudaria a explicar o estilo dos autores que produziram literatura de acordo com as exigências do jornal. Ou seja, a dinâmica adotada pelos jornais na publicação de romance-folhetim, por exemplo, com espaços delimitados e um sistema de cortes que favoreciam a continuação da história na edição seguinte, teria "contaminado" as narrativas ficcionais, que apresentam determinado resultado estético justamente porque foram levadas a isso devido ao estilo imposto pelos periódicos. Isso porque, no caso de o romance ter sido escrito de "capítulo a capítulo", o processo de criação literária provoca impasses narrativos por conta da necessidade de se manter viva a atenção dos leitores, influenciando a estrutura da obra. Existem casos, como o de Machado de Assis, em que as edições em livro trazem muitas diferenças em relação à versão do folhetim. Essas alterações nas técnicas de composição do romance "alteram o perfil do leitor ideal da revista para o livro" e também revelam "a interferência da atmosfera do veículo, a revista, no processo de criação da obra" (RIBEIRO, 2006, p. 102).

Há, ainda, interpretações que apontam para a linguagem adotada por determinado jornal ou revista, a qual pode ter "influenciado" a escrita de obras fundamentais da literatura brasileira. Em artigo recente, Lúcia Granja analisa como em Memórias póstumas de Brás Cubas, de Machado de Assis, a novidade literária é resultado, em parte, da transposição de aspectos retóricos e poéticos da escrita dos periódicos. Para Granja (2017, p. 30-31), a literatura de Machado foi "forjada nas fôrmas desse novo sistema de escrita, sendo que um dos componentes da singularidade da obra desse escritor reside no fato de haver uma profunda simbiose entre o homem, o texto e o tempo". Assim, pela sua trajetória de colaboração para os periódicos e pela refinada percepção do tempo histórico, que coloca a imprensa escrita no centro das relações entre autor, obra e público, Machado de Assis trilhou um caminho para a "novidade literária, pela profunda compreensão dos suportes/ veículos em que o escritor-jornalista atuou, aproveitando crítica e parodicamente os seus recursos poéticos, em um movimento contínuo." (GRANJA, 2017, p. 32).

Mamede Mustafa Jarouche, na introdução a Memórias de um sargento de milícias, de Manuel Antônio de Almeida, procura demonstrar que a sátira e a ironia presentes na seção "Pacotilha", do jornal Correio Mercantil, onde o romance foi publicado entre 1851 e 1852, são os mesmos encontrados nesta que é uma das principais obras do romantismo brasileiro. Ao contrário de boa parte das obras "sérias" do período, marcadas em geral 
- Sobre sonetos, discursos e jornais: sátira e galhofa no conto "Aurora sem dia", de Machado de Assis

pelos "traços idealizantes" (JAROUCHE, 2006, p. 49), Memórias de um sargento de milícias caracteriza-se por ser um romance que procura apresentar o contexto social carioca de forma cômica. Apesar de trazer poucos referenciais históricos, tampouco características descritivas, a narrativa revela tipos pitorescos representados a partir dos estereótipos identificados com os "hábitos populares" (JAROUCHE, 2006, p. 54). Dessa forma, mesmo ao ter muitas diferenças em relação aos demais textos românticos da época, o romance de Almeida é obra de seu tempo. E essa perceptível relação entre tempo e narrativa, na percepção de Jarouche (2006, p. 59), reside justamente na tradição humorística da imprensa local, na medida em que "a leitura dos jornais cômicos, muito comuns então, mostra grande semelhança com os padrões humorísticos das Memórias [...]”.

O Correio Mercantil foi um importante jornal do Rio de Janeiro, que circulou entre 1848 e 1868. Nesse jornal, Machado de Assis publicou suas primeiras crônicas, no início de carreira, além de trabalhar como revisor. Além de Machado e Manuel Antônio de Almeida, outros escritores brasileiros e estrangeiros também publicavam no Correio, como José de Alencar e Joaquim Manuel de Macedo. José de Alencar, a partir de 1854, assina nesse jornal uma coluna intitulada "Ao correr da pena". O jornal tinha apenas quatro páginas, e duas delas - primeira e segunda - eram dedicadas aos gêneros literários, incluindo uma seção exclusiva para folhetins, que geralmente ocupava o rodapé das duas páginas.

Identificado com os liberais, o Correio Mercantil era um dos jornais melhor estruturados da capital do Império, rivalizando com o Jornal do Comércio e o Diário do Rio de Janeiro. Entre 1851 e 1854, aos domingos, o jornal destinava a maior parte de seus espaços à seção "Pacotilha". Assim, o jornal tinha uma característica bem peculiar: de terça a sábado era sério e sisudo, atacando o Partido Conservador e censurando os atos políticos do governo; aos domingos assumia um tom galhofeiro, utilizando-se de gêneros literários como a crônica e a poesia para atacar os que de alguma forma exerciam o poder (JAROUCHE, 2006). Os romances-folhetim, não raro, também seguiam a linguagem do jornal. Ou seja, apostavam na narrativa satírica para manter a identificação entre o público leitor e o estilo ferino da publicação.

Por isso, não pode ser visto como um mero acaso o fato de o Correio Mercantil ser o jornal em que o protagonista do conto "Aurora sem dia", de Machado de Assis, publica suas primeiras poesias. Publicado em 1870 no Jornal das Famílias e em 1873 na coletânea Histórias da meia-noite (1873), "Aurora sem dia" aborda dois temas caros ao momento em que foi escrito: política e literatura. Nesse conto, Machado de Assis ironiza a vaidade de poetas de pouco talento e a falta de seriedade na política brasileira na figura de Luís Tinoco, um jovem que de um dia para outro descobre-se escritor e ascende a deputado com discursos vazios ensaiados nas páginas de jornais. Nesse sentido, a história aborda, 
na figura de Luís Tinoco, a formação de personalidades com vocação duvidosa e que encontram nas páginas dos jornais um espaço privilegiado de difusão de suas fantasias.

Empregado do foro, 21 anos de idade, Luís Tinoco certo dia pela manhã "acordou escritor e poeta". Segundo o narrador, seu primeiro soneto tinha como principal defeito "ter cinco versos com sílabas de mais e outros cinco com sílabas de menos". Orgulhoso de sua obra, Luís Tinoco leva a produção ao jornal Correio Mercantil, que a publica entre os "a pedidos". A segunda medida do poeta foi levar o poema ao padrinho Anastácio, a quem estimava e cuja opinião seria importante para a manutenção de seus anseios:

Leu hoje o Correio Mercantil, meu padrinho? perguntou ele.

- Homem, tu sabes que eu só lia os jornais no tempo em que era empregado efetivo.

Desde que me aposentei não li mais os periódicos...

- Pois é pena! disse Tinoco com ar frio; queria que me dissesse o que pensa de uns versos que lá vêm.

- E de mais a mais versos! Os jornais já não falam de política? No meu tempo não falavam de outra coisa.

- Falam de política e publicam versos, porque ambas as coisas tem entrada na imprensa.

Quer ler os versos?

- Dá cá.

- Aqui estão.

(ASSIS, 1997, p. 221)

O excerto anterior indica ao menos dois comentários que revelam a comicidade da situação. Ao afirmar que "[...] eu só lia nos jornais no tempo em que era empregado efetivo", Anastácio revela que passava as horas de trabalho lendo os jornais, o que não deixa de ser uma crítica ao comportamento dos funcionários públicos. Já quando questiona se "Os jornais já não falam de política?", o padrinho demonstra surpresa com a abertura do jornal para a publicação de poesia, já que estava acostumado a folhear os jornais em busca de assuntos da política. Como se sabe, o período de circulação do Correio Mercantil coincide com a explosão dos romances-folhetim na imprensa brasileira, cujo modelo importado da França amplia e garante a fidelidade dos leitores fisgados pelo modelo do "continua amanhã".

O padrinho, inicialmente sem saber a quem pertencia a obra poética, acha tudo sem graça e fica surpreso ao saber que o rapaz de repente se tornara um poeta. Luís 
- Sobre sonetos, discursos e jornais: sátira e galhofa no conto "Aurora sem dia", de Machado de Assis

Tinoco, no entanto, necessita da opinião de uma "autoridade", no caso o Dr. Lemos. Para este, o poeta apresenta um soneto e uma ode, os quais apresentavam "Imagens safadas, expressões comuns, frouxo alento e nenhuma arte", mas, apesar disso "havia de quando em quando algum lampejo que indicava da parte do neófito propensão para o mister; podia ser ao cabo de algum tempo um excelente trovador de salas." (ASSIS, 1997, p. 222). O poeta, então, mostra a sua produção ao Dr. Lemos com certa ansiedade:

O Dr. Lemos disse-lhe com franqueza, que a poesia era uma arte difícil e que pedia longo estudo; mas que, a querer cultivá-la a todo o transe, devia ouvir alguns conselhos necessários.

$[\ldots]$

- Não me parecem bons estes versos, disse o Dr. Lemos; poderia rasgá-los e estudar antes algum tempo.

Não é possível descrever o gesto de soberbo desdém com que Luís Tinoco arrancou os versos ao doutor e the disse:

- Os seus conselhos valem tanto como a opinião de meu padrinho. Poesia não se aprende; traz-se do berço. Eu não dou atenção a invejosos. Se os versos não fossem bons, o Mercantil não os publicava. (ASSIS, 1997, p. 222).

Mediadora dos desvarios do poeta romântico neste conto, a seção "Publicações a pedidos", que era paga, publicava textos dos leitores com os mais diversos conteúdos: recados para vizinhos ou autoridades, agradecimentos, reclamações, convites para acerto de contas, convocações e opiniões de toda ordem. Geralmente essa seção ocupava a parte menos nobre do jornal, na terceira ou na quarta página. Portanto, a afirmação de Luís Tinoco, de que "Se os versos não fossem bons, o Mercantil não os publicava", denota a ironia em torno da ingenuidade do personagem, na medida em que na seção de "a pedidos" o jornal publicava qualquer coisa que fosse paga - e Machado sabia disso.

José Alcides Ribeiro observa nas páginas do Correio Mercantil que a seção intitulada "Pacotilha" distinguia-se das outras seções do jornal porque misturava com muita qualidade o estilo jornalístico com o literário, usando como ferramenta o tom extremamente satírico (RIBEIRO, 2005, p. 7). Ribeiro identifica no tipo de linguagem da seção algo extremamente próximo do estilo de Manuel Antônio de Almeida, que publicava com frequência no jornal. "É importante perceber que na atmosfera midiática do Correio Mercantil o tom de crítica aos costumes e o emprego da ironia aparecem não só nas crônicas e nos outros gêneros noticiosos, mas também estão presentes nos textos ficcionais de escritores do Correio Mercantil, dentre eles, Manuel Antônio de Almeida e Joaquim Manuel de Macedo, isto aponta para a presença de um fenômeno de contaminação de um gênero textual no outro e vice-versa." (RIBEIRO, 2005, p. 9). 
Nesse sentido, pode-se especular se o emprego da ironia ao se abordar os costumes da época, que teria contaminado a escrita de Manuel Antônio de Almeida e Joaquim Manuel de Macedo por causa de sua proximidade com o jornal, não explicaria também o recurso da linguagem satírica de Machado de Assis no conto "Aurora sem dia" e em outros textos dessa época. Afinal, além de ter trabalhado e publicado crônicas no Correio Mercantil, o que permite inferir sobre a proximidade dos estilos do jornal e do escritor, Machado cita diretamente o jornal na história de Luís Tinoco. Ou seja, a escolha dessa publicação não parece ser ao acaso, na medida em que a reconhecida galhofa do narrador machadiano também era uma característica da linha editorial do jornal carioca.

Entretanto, é curioso observar que a linguagem satírica do conto não tem a ver com a linha editorial do Jornal das Famílias, onde a narrativa foi publicada, a qual vai justamente na direção contrária do Correio Mercantil. Comandado pelo editor Baptiste Louis Garnier, o Jornal das Famílias circulou no Rio de Janeiro entre 1863 e 1878. Empreendimento voltado para o público feminino, o jornal procurava ao mesmo tempo entreter, instruir e educar as leitoras, de forma que havia uma preocupação de não entrar em conflito com os modelos de comportamento a serem seguidos pela sociedade oitocentista. Em seções como "Moda" e "Romances e Novellas", salvo exceções, as mulheres são sempre as destinatárias da produção literária ou jornalística, tanto que elas são as protagonistas e muitas vezes também dão título às narrativas (PINHEIRO, 2007, p. 142). Juntamente com a tendência amorosa das histórias, a discussão de temas importantes como a nacionalidade e o abolicionismo, entre outros, também fazia parte do escopo do Jornal das Famílias. Isso leva Pinheiro (2007, p. 244) a concluir que "Ele [Jornal das Famílias] não é apenas um jornal de moralização, é também local de debate das grandes questões literárias do século XIX. Seus colaboradores, ao que parece, consideravam as mulheres como interlocutoras à altura desse debate.". A seriedade do jornal, portanto, contrasta com o Correio Mercantil, que também abordava essas questões, mas, para isso, usava o recurso do sarcasmo.

No conto de Machado, após o repentino aparecimento dos poemas de Luís Tinoco nos "a pedidos" do Correio Mercantil, não demora para que outros jornais fiquem "cheios de produções suas, umas tristes, outras alegres, não daquela tristeza nem daquela alegria que vem diretamente do coração, mas de uma tristeza que fazia sorrir, e de uma alegria que fazia bocejar." (ASSIS, 1997, p. 223). Motivado pela recepção da imprensa, Luís Tinoco logo cria a sua própria publicação, o "Caramanchão Literário", e cinco meses mais tarde já tem poemas suficientes para reuni-los em um livro, publicado com o título de "Goivos e Camélias". A reação geral é de zombaria, mas para ele os ataques eram "de invejosos". Segundo o narrador de "Aurora sem dia", apenas um folhetinista entre tantos jornais que circulavam à época escreveu sobre ele "algumas linhas que fizeram rir a toda a gente, 
- Sobre sonetos, discursos e jornais: sátira e galhofa no conto "Aurora sem dia", de Machado de Assis

menos o autor, que foi agradecer ao folhetinista". (ASSIS, 1997, p. 225). Para o narrador, "Os versos falavam de tudo, da morte e da vida, das flores e dos vermes, dos amores e dos ódios; havia mais de oito ciprestes, cerca de vinte lágrimas, e mais túmulos do que um verdadeiro cemitério." (ASSIS, 1997, p. 224).

Nesse trecho fica evidente que a crítica se volta para os poetas românticos de qualidade duvidosa. Luís Tinoco de fato "confessava singelamente ao mundo que fora invadido do ceticismo byroniano" (ASSIS, 1997, p. 223). Os temas relacionados à vida e à morte, amores e ódios, alegria e sofrimento, entre outros, são os mais comuns na poesia romântica e nos romances de folhetim que circulavam à época. O próprio Machado, nos seus primeiros poemas, não deixa de explorar esses temas. No entanto, o escárnio com que Luís Tinoco é apresentado, vítima do riso alheio e mesmo assim confiante na sua capacidade criativa, mostra certa inclemência do escritor com os poetas de "a pedidos".

Prova da crítica à efemeridade de certos poetas está na própria sequência do conto. Passado esse momento de exibição literária nos jornais e na obra "Goivos e Camélias", o ímpeto poético de Luís Tinoco arrefece e ele decide abandonar os versos e entrar para a política com a ajuda do Dr. Lemos. Sua ambição era ser deputado e, para ser bem-sucedido, precisa escrever discursos. Da mesma maneira que acreditava ser um grande poeta incompreendido, Luís Tinoco acredita agora ter nascido com a vocação de endireitar a política. Sua estreia na arte da oratória política termina da seguinte maneira:

Releve o poder, - hipócrita e sanhudo, - que eu lhe diga muito humildemente que não temo o desprezo nem o martírio. Moisés conduzindo os hebreus à terra da promissão, não teve a fortuna de entrar nela: é o símbolo do escritor que leva os homens à regeneração moral e política, sem lhe transpor as portas de ouro. Que poderia eu temer? Prometeu atado ao Cáucaso, Sócrates bebendo a cicuta, Cristo expirando na cruz, Savonarola indo ao suplício, John Brown esperneando na forca, são os grandes apóstolos da luz, o exemplo e conforto dos que amam a verdade, o remorso dos tiranos, e o terremoto do despotismo. (ASSIS, 1997, p. 230).

A tentativa de fazer um discurso persuasivo que convença os colegas do plenário sobre o seu destemor diante dos desafios da política revela apenas um recado vazio de sentido, em que a citação de grandes nomes da história na humanidade não permite apreender o verdadeiro sentido das palavras. Mais adiante, na sua primeira candidatura em uma eleição primária, como oposição ao governo, Luís Tinoco não consegue se eleger. Então ele aposta em outro gênero, o artigo, utilizando-se mais uma vez do jornal para atacar os adversários. A resposta vem em seguida: "Até onde quererá ir, com 
semelhante descomedimento de linguagem, o pimpolho do ex-deputado Z.?". O ataque dos governistas é recebido com júbilo pelo jovem orador, que vê na polêmica uma oportunidade de se fazer ouvir. Tinoco acreditava que a imprensa nunca o havia tratado com a consideração merecida e, para ele, "faltava o ataque pessoal, que lhe parecia ser o batismo de fogo naquela espécie de campanha" (ASSIS, 1997, p. 230). Nessa ocasião, Luís Tinoco responde com um longo artigo sobre o que era e o que não era ser um pimpolho.

Dois anos mais tarde, encontra-se Luís Tinoco eleito deputado estadual. Sua habilidade oratória, por sua vez, mostra-se cada vez mais acurada. Observa o narrador que em uma de suas primeiras sessões ele faz um discurso de duas horas para demonstrar, por A + B, que a água era necessária ao homem, a propósito de um projeto sobre a colocação de um chafariz. Ao tratar de questões orçamentárias, "a receita foi comparada ao orvalho que as flores recolhem durante a noite; a despesa à brisa da manhã que sacode e thes entorna um pouco do sereno vivificante." (ASSIS, 1997, p. 230).

Embora a poesia tenha ficado no passado, restando apenas o estilo prolixo e a incapacidade de criar metáforas convincentes, aquilo que foi registrado, tanto em jornais quanto em livros, não pode mais ser apagado. E eis que um deputado da oposição, após um desses discursos de Luís Tinoco, sobe à tribuna com um maço de jornais e um folheto. O deputado pede permissão para ler um dos poemas publicados na obra "Goivos e Camélias". A intenção do parlamentar é atacar a imagem de Luís Tinoco, não ao tornar público algum crime ou deslize moral, mas, sim, revelando aos colegas a sua produção literária de outrora:

A ela.

Quem és tu que me atormentas

Com teus prazenteiros sorrisos?

Quem és tu que me apontas

As portas dos paraísos?

Imagem do céu és tu?

És filha da divindade?

Ou vens prender em teus cabelos

A minha liberdade?

(ASSIS, 1997, p. 233)

Após ler o poema, o deputado afirma: "Vê V. Exa., Sr. presidente, que nesse tempo, o nobre deputado era inimigo de todas as leis opressoras. A assembléia tem visto 
- Sobre sonetos, discursos e jornais: sátira e galhofa no conto "Aurora sem dia", de Machado de Assis

como ele trata as leis do metro."4. Pior do que os risos que tomaram conta da sessão, foi a repercussão nos jornais no dia seguinte. A ironia na voz do narrador mostra-se mais uma vez no registro de um desses jornais, que agradece ao adversário de Luís Tinoco por ter revelado à província "uma antiga e brilhante face do talento do ilustre deputado." (ASSIS, 1997, p. 233). Nesse momento, Luís Tinoco tem a atenção que sempre desejou da imprensa carioca, mas não pelos motivos que gostaria. Se antes os seus escritos estavam restritos aos espaços de "a pedidos", agora ele ocupa um lugar mais nobre dos jornais. No entanto, os periódicos reaparecem para zombar de sua eloquência de parlamentar e de sua produção literária.

Percebe-se, então, que o conto "Aurora sem dia" satiriza a figura tanto do poeta quanto do político. Em relação ao primeiro, está implícita uma crítica aos poetas românticos que de um dia para outro descobrem-se escritores - como o próprio Machado, aos 16 anos de idade -, produzem de forma rápida e reagem às críticas negativas com o argumento da incompreensão. E o sofrimento advindo do escárnio reforça a postura melancólica do poeta. Quanto ao segundo, a crítica volta-se aos discursos vazios dos parlamentares e sua capacidade de falar muito para dizer pouco. Em sua juventude, mais precisamente a partir de 1861, Machado de Assis passou a integrar a equipe de redação do jornal Diário do Rio de Janeiro, atuando primeiramente como redator do noticiário e repórter do Senado. Esse universo, portanto, era bem conhecido do escritor.

A sátira presente no conto de Machado de Assis, para revelar os defeitos de Luís Tinoco como poeta e parlamentar, tem como referencial histórico a presença dos jornais, especificamente o Correio Mercantil. Embora não se perceba uma crítica ao jornal diretamente, a construção do arquétipo do escritor de raro talento e do político enfadonho passa necessariamente pela imprensa. É ali que ambos procuram tanto o reconhecimento e o aplauso quanto a controvérsia que leva à oportunidade de se manter sempre lembrado.

Em "Aurora sem dia", bem como em outros escritos de Machado de Assis, percebese que a linguagem da imprensa da época reverbera de alguma forma na linguagem da narrativa literária. Afinal, havia um cuidado por parte de editor e escritor de manter certa coerência editorial para garantir a fidelidade do leitor, mesmo em relação ao texto literário. Esse conto, embora tenha sido publicado no Jornal das famílias, faz referência direta ao Correio Mercantil, periódico caracterizado por utilizar a galhofa para provocar os

\footnotetext{
4 Em 1855, aos 16 anos de idade, Machado de Assis publicou o poema "Ela" no jornal Marmota Fluminense, o qual é considerado a sua primeira publicação. A semelhança entre os títulos e o tema dos poemas pode ser vista também como uma espécie de autoironia do escritor. Afinal, ele também foi apressado ao publicar os primeiros versos e deve ter sentido a mesma alegria do personagem Luís Tinoco ao ver o poema no jornal.
} 
adversários. Não parece ser apenas uma coincidência a escolha desse jornal em particular para apresentar as aventuras de Luís Tinoco pela literatura e pela política. Nesse sentido, trata-se menos de um resultado estético em que a linguagem ficcional espelha a linguagem jornalística de forma direta, ou seja, o texto que segue o modelo do meio em que vincula, e mais de uma representação do universo da imprensa. O que não deixa de fortalecer a ideia de que as relações entre o jornal e a literatura vão muito além das contribuições no campo da difusão e da recepção. Essas contribuições, apesar de menos evidentes, muitas vezes estão no plano dos artifícios da linguagem dos gêneros literário e jornalístico.

\section{Referências}

ALVES, M. M. Erico Verissimo e o jornalismo: fontes para a criação literária. Jundiaí: Paco Editorial, 2018.

ASSIS, M. de. Obra completa. Organizada por Afrânio Coutinho. v. II. Conto e teatro. Rio de Janeiro: Nova Aguilar, 1997.

CARDOSO, F. H. Capitalismo e escravidão no Brasil meridional: o negro na sociedade escravocrata do Rio Grande de Sul. São Paulo: DIFEL, 1962.

CARONE, E. República Velha: evolução política. 2. ed. São Paulo: Difusão Européia do Livro, 1974.

COSTA, E. V. da. Da Senzala à colônia. 5. ed. São Paulo: UNESP, 2012.

COSTA, E. V. da. Coroas de glória, lágrimas de sangue: a rebelião dos escravos de Demerara em 1823. Tradução Anna Olga de Barros Barreto. São Paulo: Companhia das Letras, 1998.

FREYRE, G. O Escravo nos anúncios de jornais brasileiros do século XIX. 2. ed. aumentada. São Paulo: Editora Nacional, 1979.

GRANJA, L. Capítulos de uma revolução: Memórias póstumas de Brás Cubas. LusoBrazilian Review, v. 54, n. 2, p. 29-44, 2017. 
- Sobre sonetos, discursos e jornais: sátira e galhofa no conto "Aurora sem dia", de Machado de Assis

JAROUCHE, M. M. Introdução: Galhofa sem melancolia: as Memórias num mundo de Luzias e Saquaremas. In: ALMEIDA, M. A. de. Memórias de um sargento de milícias. Cotia: Ateliê Editorial, 2006.

LUCA, T. R. de. História dos, nos e por meio dos periódicos. In: PINSKY, C. B. (org.). Fontes históricas. 2. ed. São Paulo: Contexto, 2008. p. 111-153.

PINHEIRO, A. S. Para além da amenidade - O Jornal das Famílias (1863-1878) e sua rede de produção. 2007. Tese (Doutorado em Teoria e História Literária) - Instituto de Estudos da Linguagem, Universidade Estadual de Campinas, Campinas, 2007.

RIBEIRO, J. A. Correio Mercantil do Rio de Janeiro: modos jornalísticos e literários de composição. XXVIII Congresso Brasileiro de Ciências da Comunicação - UERJ - 5 a 9 de setembro de 2005.

RIBEIRO, J. A. Ficção e imprensa no Brasil: os processos de criação de Machado de Assis, Joaquim Manuel de Macedo e José de Alencar. Manuscrítica, São Paulo, v. 14, p. 101-115, 2006.

ZINANI, C. J. A. (org.). Imprensa feminista e literatura: contribuições da revista "A Mensageira". Caxias do Sul: EDUCS, 2019.

COMO CITAR ESTE ARTIGO: ALVES, Márcio Miranda. Sobre sonetos, discursos e jornais: sátira e galhofa no conto "Aurora sem dia", de Machado de Assis. Revista do GEL, v. 16, n. 1, p. 164-175, 2019. Disponível em: https://revistadogel.gel.org.br/

DOI: http://dx.doi.org/10.21165/gel.v16i1.2748

Submetido em: 12/10/2019 | Aceito em: 13/11/2019. 